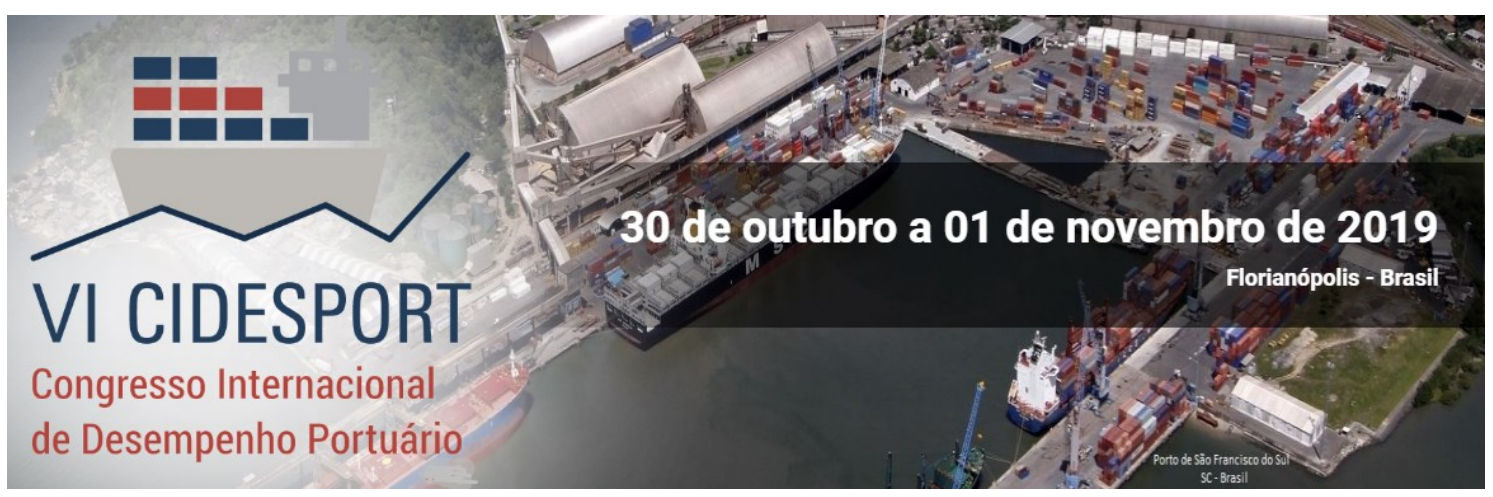

\title{
CABOTAGEM E O MEIO AMBIENTE: UM ESTUDO NO COMPLEXO PORTUÁRIO DE SÃO LUÍS
}

\author{
Lays Vaz \\ Universidade Federal do Maranhão \\ Taciana Cristina Soares Pereira \\ Universidade Federal do Maranhão \\ Darliane Ribeiro Cunha \\ Universidade Federal do Maranhão
}

Resumo: O artigo é um estudo sobre o panorama da cabotagem e o meio ambiente no Maranhão tendo em vista o projeto para retomada da linha regular de cabotagem no Porto do Itaqui, identificamos seus entraves e oportunidades. Contextualizamos o modal rodoviário que é de maior expressividade na matriz de transporte brasileira e a problematização que este oferece ao meio ambiente. Comparamos a eficiência ambiental e econômica da cabotagem em relação às rodovias. Por fim, demonstramos os resultados preliminares da pesquisa de campo realizada através de entrevistas do tipo semiestruturada junto aos gestores da empresa de administração Portuária do Maranhão e a gestora da empresa de negócios internacionais. Apontamos, enfim, que as dificuldades que o Maranhão enfrentou no passado interferem na credibilidade do projeto para os atores envolvidos, e a baixa industrialização do estado ocasiona pouco interesse de investimentos no setor, tendo em vista que o lucro ainda é o fator principal e os benefícios ambientais são consequências secundárias.

Palavras-chave: Cabotagem. Ambiental. Transporte.

\section{INTRODUÇÃO}

O Brasil possui uma matriz de transporte em desequilíbrio o que gera sobrecarga no modal rodoviário. As rodovias são responsáveis por cerca de $60 \%$ do escoamento de carga (ALVES FILHO, 2018) e este já demonstra reflexos de crise, como ocorreu na greve dos caminhoneiros, também conhecida como crise do diesel que ocorreu entre maio e junho de 2018, na qual expos para todo o mundo a dependência do setor rodoviário para a movimentação de cargas. Em todos os ramos foi possível notar reflexos da greve. Os que conseguiram continuar suas atividades utilizavam outro tipo de transporte, como os aeroportos de Guarulhos e Galeão, não sofreram com a crise do diesel, pois o querosene de aviação chega a esses aeroportos por meio de dutos (GUIMARÃES, 2018).

O transporte rodoviário emite uma grande quantidade de gás carbônico sendo este o de maior representatividade na matriz de transporte brasileira, gerando consequências em diversos setores da sociedade. Portanto não é eficiente ter estrutura geográfica para explorar o melhor de cada modal e não reestruturar a matriz

* A revisão gramatical, ortográfica, ABNT ou APA foi realizada pelos autores. 


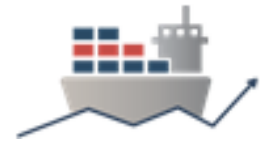

de transporte. A ideia não é condenar o transporte rodoviário, mas analisar os seus pontos fortes e usa-los a favor da logística, enquanto as suas fraquezas devem ser substituídas por um modal que possa atender a demanda cumprindo as obrigações, econômicas, sociais e ambientais.

Os Estados Unidos é um exemplo de equilíbrio no setor de transportes, possuem 41 mil quilômetros de hidrovias e utiliza $100 \%$ delas, enquanto o Brasil é responsável por 50 mil quilômetros utilizando apenas $28 \%$, segundo o banco mundial. A consequência da falta de estratégia do país em utilizar o que foi dado pela natureza a seu favor pode ser visto no Índice de Desempenho Logístico (LPI) realizado pelo banco mundial referente ao ano de 2018 . O Brasil está na $56^{\circ}$ posição enquanto os Estados Unidos ocupa a $10^{\circ}$ posição. A partir desses dados é possível perceber a necessidade de explorar de forma eficiente o território do país para favorecer o transporte de cargas. Não apenas ficando dependente das rodovias em sua totalidade, mas firmando uma parceria com a cabotagem para entrega da carga com baixo custo, menor probabilidade de perda e gerando menos ônus ao meio ambiente.

Os empresários maranhenses ainda sofrem com os reflexos que a crise trouxe para o estado, aumentos no frente despertaram na classe a necessidade de buscar uma alternativa para diminuir os custos e com isso reacendeu o interesse para retomada da linha regular de cabotagem no Porto do Itaqui, de forma modesta impulsionar o desenvolvimento do estado e torna-lo mais atrativo para receber investimentos. Nas próximas seções serão apresentados os conceitos e o cenário de cada setor que envolve o assunto, através de uma revisão bibliográfica.

$\mathrm{O}$ presente artigo tem como objetivo analisar o mercado maranhense para o efetivo uso da cabotagem tendo em vista os benefícios ambientais que poderão acarretar com o seu maior uso no transporte do estado.

\section{TRANSPORTE RODOVIÁRIO}

O modal rodoviário é majoritariamente utilizado, foi iniciado no governo do presidente Washington Luís, mas com Juscelino Kubitschek que o rodoviarismo ganhou força, com a ideia de integrar o Brasil e de atrair o setor automobilístico. Essa cultura foi crescendo, o país se adaptando, os investimentos em ferrovias e hidrovias foram menores, logo as taxas e impostos desses tornaram-se menos atrativas, com isso temos hoje a predominância rodoviária. (BRASILALEMANHA NEWS, 2016)

De acordo com um estudo da CNT (2017) o modal rodoviário oferece vantagens que atrai grande parte dos empresários brasileiros, sendo eles a flexibilidade para o transporte porta a porta; maior investimento do governo, ao comparar com outros modais; facilidade no embarque e desembarque de mercadorias, não se fazendo necessária uma estrutura especifica; maior frequência e agilidade na entrega, fator importante para o setor de produtos perecíveis.

No sentido contrário, Portogente (2016) apresenta as desvantagens do modal rodoviário que são responsáveis pela preocupação em buscar um equilíbrio do transporte brasileiro. O país não possui uma fiscalização eficiente que possa controlar as mercadorias que trafegam nas rodovias; pavimentação irregular ocasiona acidentes de trânsito; alto índice de perdas e uso de combustíveis fosseis acelera o agravamento do efeito estufa.

A ideia não é excluir o modal, mas utiliza-lo de forma consciente e com as devidas correções dos erros. Com isso é necessário que o conceito de multimodalidade seja colocado em prática. Multimodalidade é a integração dos modais utilizando apenas um documento até a carga chegar ao cliente. Affonso (2017) deixa 
claro a sua visão quanto à necessidade da pluralidade dos modais, no entanto ele não percebe que o governo tenha a mesma opinião.

É contraditório buscar um crescimento econômico, em um país que exporta uma grande quantidade de commodities e com uma forte cultura agroexportadora não pensar na reformulação dos transportes em caráter emergencial. É notória a saturação das rodovias devido a sua baixa infraestrutura e uma demanda crescente.

De $1.735 .621 \mathrm{~km}$ de rodovias no país, apenas $212.886 \mathrm{~km}(12,3 \%)$ são pavimentados, contudo oferecem baixa qualidade para a realização do transporte de pessoas e cargas de forma segura e eficiente. Isso equivale a uma densidade rodoviária de apenas $24,8 \mathrm{~km}$ para cada $1.000 \mathrm{~km} 2$ de área territorial. Ou seja, cerca de 17 vezes menor do que a densidade nos EUA (438,1 km para cada $1.000 \mathrm{~km} 2$ de área territorial). (CNT, 2018)

A pavimentação inadequada gera maior tempo de viagem e consequente maior emissão de gases nocivos, foi o que afirmou Bartholomeu e Caixeta-Filho (2008) em questões econômicas uma boa pavimentação pode proporcionar uma redução no consumo médio de combustível em até $7,8 \%$ ao tratar-se de fatores ambientais é possível notar uma redução de $2 \mathrm{~g} \mathrm{CO} 2$ por tonelada transportada a cada quilômetro, foi o que concluíram com a pesquisa. Com isso chama atenção para outro ponto de grande preocupação mundial o aumento da emissão de gás carbônico que provoca o efeito estufa. Segundo um estudo realizado pela CNT em 2018, a frota de veículos possui uma idade elevada, o problema se torna maior quando falamos sobre os caminhoneiros autônomos, que devido o seu baixo poder de investimento a idade média dos veículos é de 23,4 anos. Rodovias com problemas estruturais somando a veículos ultrapassados de alto consumo de combustível geram problemas ambientais que são diretamente proporcionais a estes agravantes. A resolução dessas problemáticas não envolve apenas o setor ambiental, mas a economia terá grandes benefícios que serão refletidos no custo final dos produtos, conforme a pesquisa realizada pela CNT em 2015.

Somente o treinamento de motoristas de caminhão pode gerar $12 \%$ ou mais de economia de diesel. Essa redução torna-se ainda mais significativa ao se considerar que o diesel é o principal insumo do setor. O gasto com combustível representa cerca de $30 \%$ a $40 \%$ do custo operacional do transporte rodoviário de cargas.

Figura 1 - Matriz de Transporte Brasileira em 2017

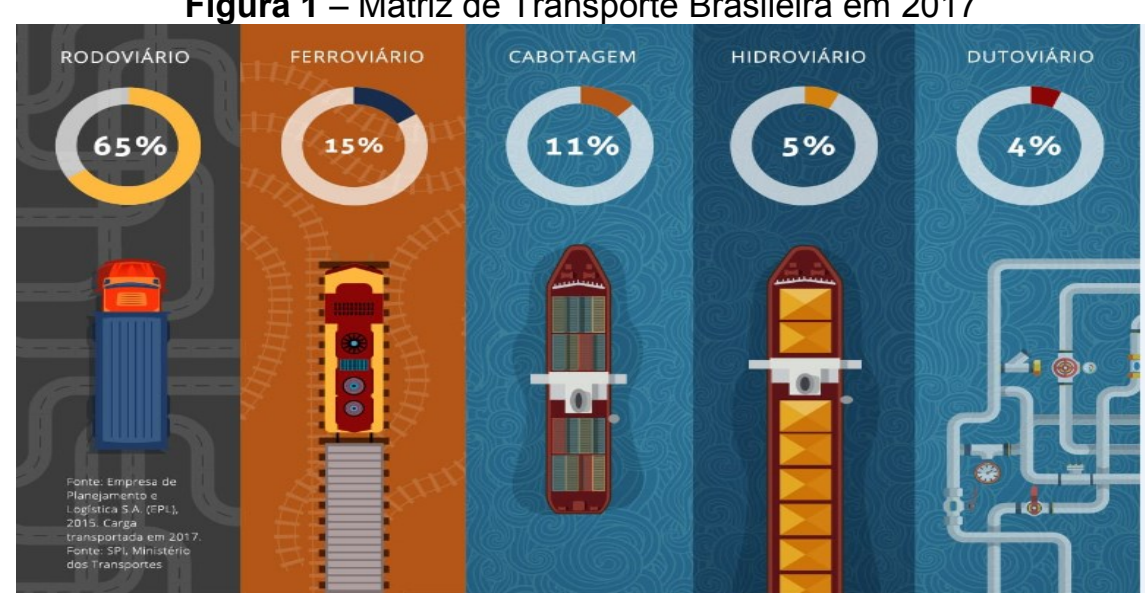

Fonte: Portal da Intermodalidade Caminhos do Brasil, 2019. 
Diferente de outros países como China e Estados Unidos que utilizam o transporte explorando o melhor que cada um tem a oferecer, levando em consideração sua geografia atrelada a um planejamento eficaz, o Brasil ainda permanece como antagonista, com sua matriz desequilibrada conforme Figura 1, dificultando a disputa dos nossos insumos no mercado internacional, por conseguinte contribuindo para a degradação do meio ambiente.

Com esses dados é possível notar a necessidade de um politica resolutiva para o setor de transportes, os problemas estão tomando grandes proporções e atingindo diversos setores, e as consequências de alguns deles podem ser irreversíveis como é o caso do efeito estufa.

\section{EMISSÕES DE DIÓXIDO DE CARBONO}

Ao contrário do que muitos pensam o efeito estufa não é um fenômeno que traz malefícios quando controlado, sua função é deixar a temperatura da terra agradável, através de gases naturais, sem eles estaríamos enfrentando um frio severo. No entanto foi percebido que a camada de gases está ficando mais expeça o que impede a dissipação do calor, ocasionando o seu aprisionamento e consequentemente o aumento de temperatura da terra. Um dos gases responsáveis por esse efeito é o dióxido de carbono ou gás carbônico que está presente nos combustíveis fósseis. (MINISTÉRIO DO MEIO AMBIENTE, 2019)

Figura 2 - Emissão de Poluentes

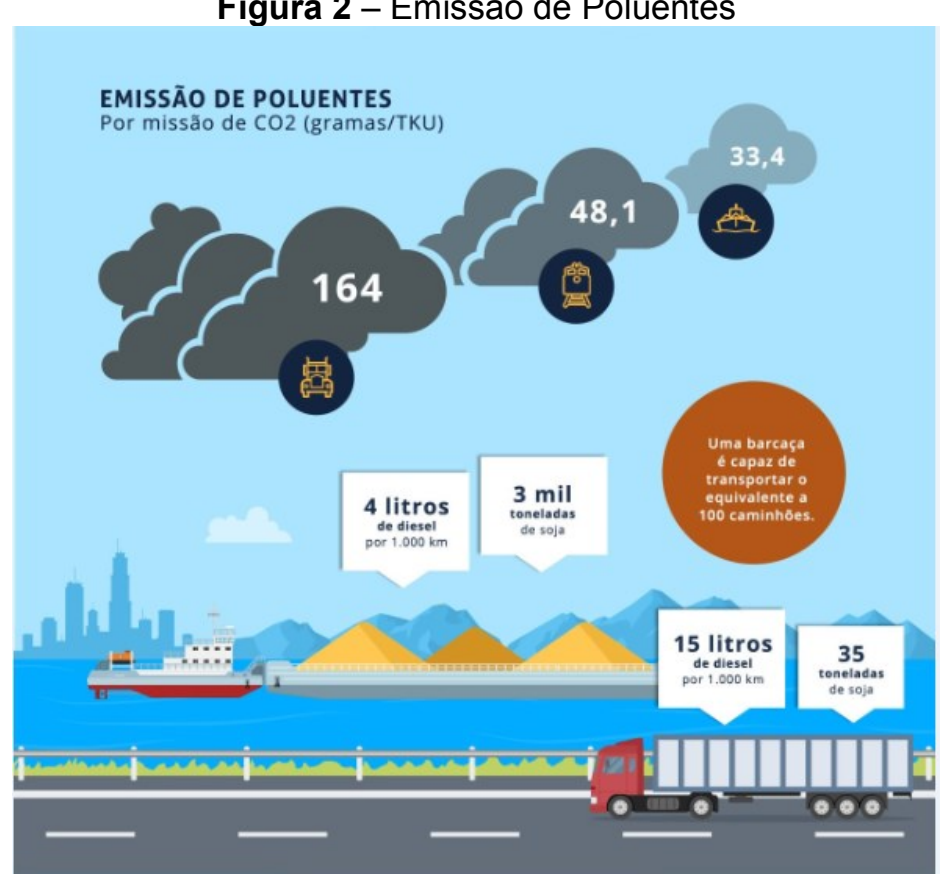

Fonte: Portal da Intermodalidade Caminhos do Brasil, 2019.

Vários fatores influenciam para o aumento dos gases que provocam o efeito estufa, um deles é a energia, que esta ligada diretamente aos combustíveis, a figura 2 ilustra a emissão de poluentes de acordo com cada modal. Estudiosos já alertam quanto à necessidade do uso de energias renováveis. Tecnologias estão sendo implantadas em veículos para melhorarem sua autonomia, tudo isso devido a uma pressão do setor ambiental e também da necessidade de menor custo. Em 2015 a CNT realizou uma pesquisa com 292 entrevistados, sendo eles proprietários de empresas, diretores e gerentes através de uma sondagem da eficiência energética do 
VI CIDESPORT/2019

Congresso Internacional

de Desempenho Portuário

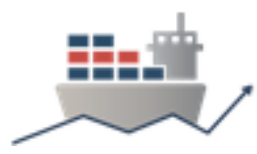

transporte rodoviário de cargas, nela foi possível perceber as fraquezas desse setor e as medidas que estão sendo tomadas para diminuir a emissão de poluentes.

A maior parte das empresas $(74,6 \%)$ adota alguma tecnologia nos veículos para economizar. Os equipamentos mais comuns são os chamados defletores aerodinâmicos, que são colocados em diferentes partes do caminhão para reduzir a resistência do ar e permitir, assim, menor gasto de combustível. $67,4 \%$ das empresas utilizam defletores no teto e $51,8 \%$ nas laterais. O sistema de enchimento automático de pneus e as rodas de ligaleve são escolhidos por $36,7 \%$ e $35,8 \%$, respectivamente.

O ministério do meio ambiente lançou o programa RenovaBio através da lei $\mathrm{n}^{\circ}$ 13.576/2017 com a ideia de estimular a produção de biocombustível para inserir mais energia renovável na matriz energética brasileira. Como, o transporte rodoviário é o mais utilizado e esse necessita de combustíveis fósseis, logo aumenta sua produção, criando assim um cenário de alerta ambiental. No entanto segundo Bartholomeu, Péra e Caixeta-Filho (2015) o desenvolvimento de tecnologias para melhorar o desempenho dos veículos é de extrema importância para que resultados significativos sejam alcançados, caso contrário à busca por biocombustível não terá relevância, tendo em vista sua baixa eficiência nos veículos que não foram projetados para receber tal combustível.

\section{CABOTAGEM}

A cabotagem consiste em uma navegação realizada entre portos de um mesmo país. O Brasil possui mais de 8 (oito) mil km de costa navegável o que facilita o transporte desse tipo como mostra a figura 3 . Ainda é pouco utilizada, mas possui um futuro promissor, contribuindo para a cadeia de suprimentos das empresas que estão próximas ao porto, isto posto o desenvolvimento local é um fator considerável. (GONÇALVES et al., 2011) 
Figura 3 - Infraestrutura Portuária

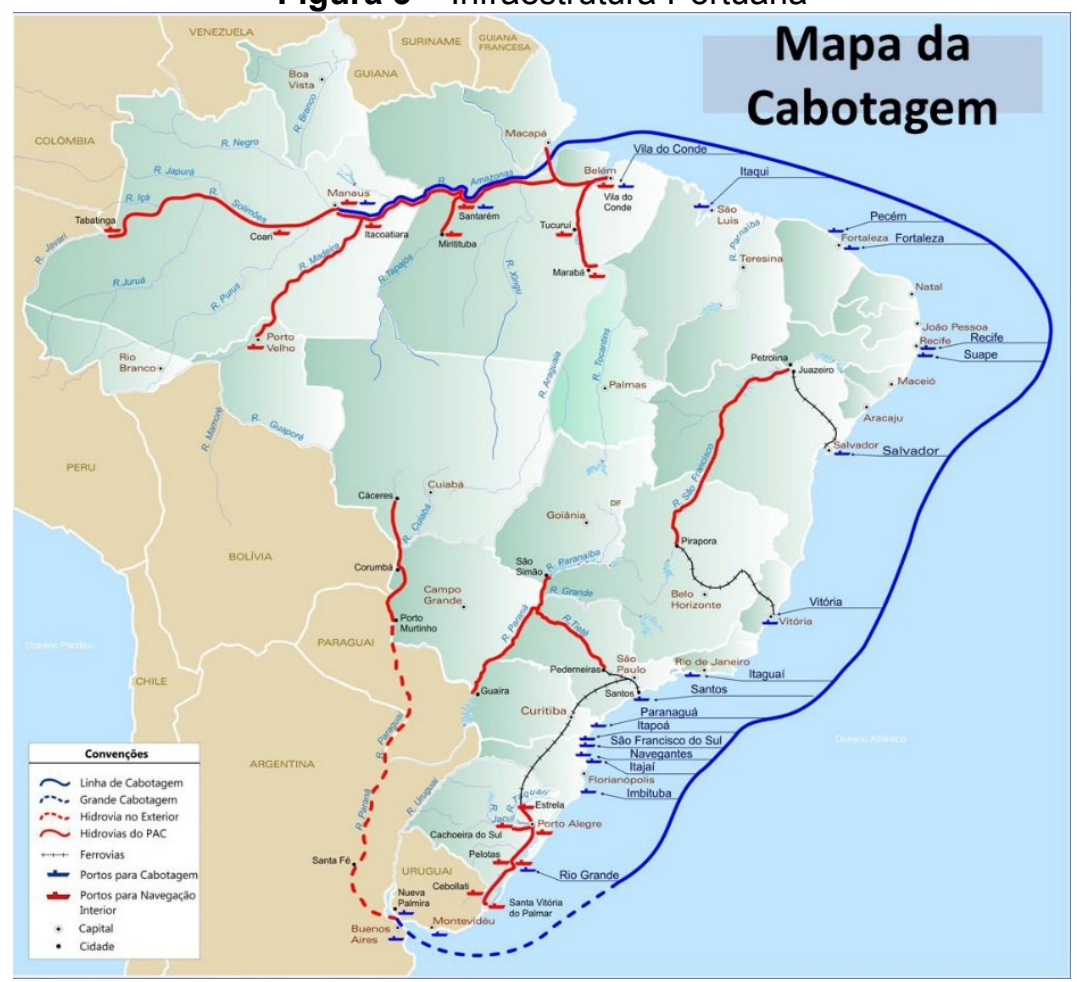

Fonte: IBL Frenlogi, 2019.

A reestruturação do setor de transportes visando eficiência energética e produtividade não é algo simples, TEIXEIRA (2018) alerta sobre a necessidade de buscar tratativas para questões como:

- Falta de eficiência portuária e as altas tarifas incidentes no setor (como carregamento, descarregamento e armazenagem de mercadorias);

- Burocracia nas operações em portos é maior como compara a Figura 4;

- Complexa tributação;

- Poucas rotas regulares, e ainda possuem baixa frequência;

- infraestrutura portuária inadequada para um transporte intermodal.

Figura 4 - Transporte Rodoviário x Cabotagem

\begin{tabular}{|c|c|}
\hline $\begin{array}{l}\text { Rodoviário } \\
\text { Conhecimento de Transporte } \\
\text { Rodoviário de Carga (CTRC) } \\
\text { - Nota Fiscal da Carga } \\
\text { Controles - apenas do } \\
\text { SEFAZ }\end{array}$ & $\begin{array}{l}\text { Cabotagem } \\
\text { - Conhecimento de Transporte } \\
\text { Aquaviário de Carga (CTAC) } \\
\text { - Nota Fiscal da Carga } \\
\text { - Controles } \\
\text { - SEFAZ } \\
\text { - Sistema Mercante } \\
\text { - Siscomex Carga }\end{array}$ \\
\hline $\begin{array}{c}\text { Sem Burocracia e maiores } \\
\text { controles }\end{array}$ & $\begin{array}{l}\text { Necessidade de diminuir a } \\
\text { Burocracia }\end{array}$ \\
\hline
\end{tabular}

Fonte: ANTAQ, 2009.

Apesar de exigir certas mudanças a cabotagem vem se mostrando necessária. Segmentos importantes ganhariam com seu uso mais efetivo, como afirma Gonçalves 
(2011) à cabotagem não possui apenas benefícios comerciais, mas o setor ambiental terá resultados relevantes. A transferência do transporte da terra para o mar possibilitará alterações positivas no nível de poluição. A diminuição da emissão de Co2 torna possível tratar com empresas estrangeiras que participam de tratados como o Protocolo de Quioto, para negociar créditos de carbono (ANTAQ, 2009).

A quantidade de empresas e principalmente caminhoneiros autônomos que buscam medidas para redução dos gases nocivos ainda é muito pequeno, tanto que os resultados não são animadores. Um comparativo de 2016 a 2017 houve um aumento na emissão pela queima de combustível. Em 2016 foi emitido 399.434.411m em 2017 teve um total de 406.224.573m como mostra o gráfico da figura 5 (SEEG Brasil, 2017).

Figura 5 - Emissão de gases pelo setor de transporte

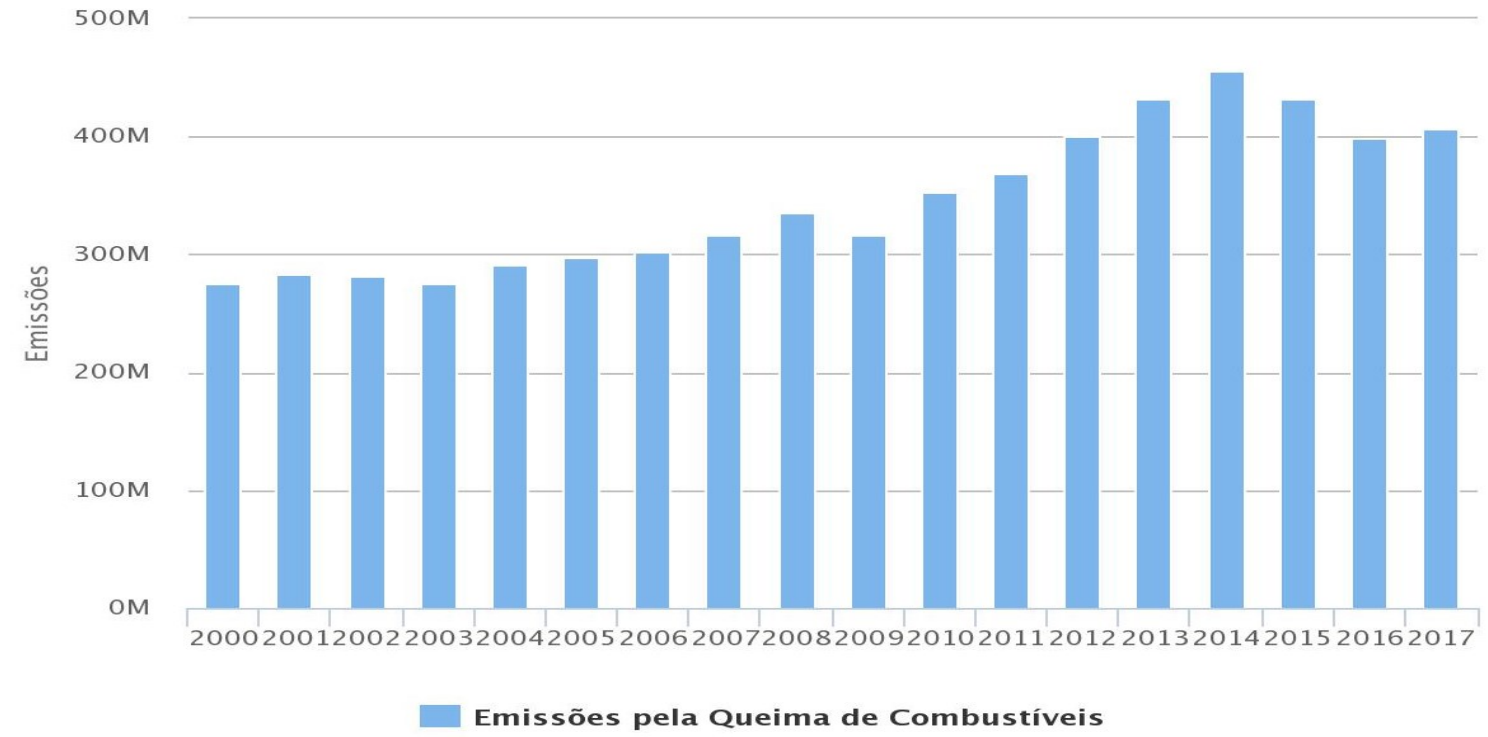

Fonte: SEEG Brasil, 2017.

No dia 15 de março de 2019 houve uma reunião entre representantes da ANTAQ junto a Associação Brasileira dos Armadores de Cabotagem (Abac), que foi exposto um estudo sobre eficiência energética do transporte entre portos. A navegação de cabotagem emite quatro vezes menos poluente que o transporte rodoviário. Há, ainda, um potencial de economia de $\mathrm{R} \$ 1,7$ bilhão por ano no frete. Além disso, poderia haver redução de dez mil acidentes nas estradas brasileiras ao ano a partir do efetivo uso da cabotagem.

BORGES at al (2018) explica que existe uma eficiência energética desde que se traçarmos a relação combustível $x$ tonelagem, após esta analise pode-se observar que é ambientalmente sustentável pela retirada da emissão de CO2 nas estradas, se comparado a modais rodoviários. Sousa (2018) compartilha da mesma opinião e concluiu em seu estudo a eficiência da cabotagem em relação ao volume, que se mostrou mais competitivo que o transporte rodoviário, a capacidade em peso transportado através dos contêineres supera o número de veículos carregados, tendo uma significativa redução no número de viagens em rodovias.

Agência de Proteção Ambiental realizou um comparativo e este foi divulgado pelo DNIT. Há uma discrepância entre os transportes de cargas quanto à emissão de poluente, como pode ser analisado na tabela 1. 


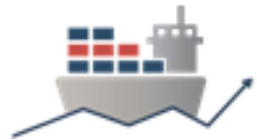

Tabela 1- Quilos poluentes produzidos no transporte de 1 tonelada de carga na distância de 1.609,34 $\mathrm{Km}$ (1.000 milhas)

\begin{tabular}{|c|c|c|c|}
\hline Modo & Hidrocarbonetos & $\begin{array}{c}\text { Monóxido de } \\
\text { Carbono }\end{array}$ & Oxido nitroso \\
\hline $\begin{array}{c}\text { Empurrador } \\
\text { (hidrovia) }\end{array}$ & $0,041 \mathrm{~kg}$ & $0,091 \mathrm{~kg}$ & $0,240 \mathrm{~kg}$ \\
\hline Trem & $0,21 \mathrm{~kg}$ & $0,29 \mathrm{~kg}$ & $0,83 \mathrm{~kg}$ \\
\hline Caminhão & $0,286 \mathrm{~kg}$ & $0,862 \mathrm{~kg}$ & $4,613 \mathrm{~kg}$ \\
\hline
\end{tabular}

Fonte: Agência de Proteção Ambiental - Lab. De Controle de Emissão - EUA.

Mesmo o transporte hidroviário sendo o menos agressivo ao meio ambiente, ainda existe receio em utiliza-lo. Em uma pesquisa realizada por Catela e Seabra (2017) para discutir o melhor transporte entre São Paulo e Manaus tendo em vista seus mercados, foi percebido, para que haja a transferência do modal rodoviário para a cabotagem alguns fatores precisam haver mudanças, como o frete, transit time e confiabilidade, assim como o porte da empresa e o valor agregado do produto também são pontos decisivos na escolha. Em contrapartida para Fachinello e Nascimento (2008) o frete da cabotagem não é mais um entrave, montando uma estratégia aliando-o ao rodoviário, é possível obter menor custo.

É interessante analisar o contraste entre as opiniões tendo em vista um período longo entre elas, o que comprova a falta de homogeneidade do transporte no país e a discreta evolução.

Segunda a ANTAQ (2019) a navegação por cabotagem aumentou em 2018 $2,98 \%$. A partir do evento que ocorreu deixando grande parte do país desabastecido, é possível que um momento trágico tenha servido como alerta para a necessidade da mudança.

BOTTER (2011) discorre sobre fatores cruciais para que haja um bom desenvolvimento da cabotagem como: analisar a cabotagem sempre de forma integrada aos demais modais, e ainda sendo realizado um serviço porta-a-porta; fomentar as vantagens do transporte através de campanhas institucionais, tanto para usuários quanto aos operadores logísticos interessados em ingressar no setor.

A esse respeito, Silveira (2015) declara:

35 portos públicos nacionais, apenas doze tem serviços regulares de cabotagem e com um reduzido número de rotas destinadas ao transporte de carga. Uma forma de chamar mais atenção do mercado e solução oferecida pelos principais armadores se trata da logística porta-a-porta, o que tem estimulado a mudança do transporte de cargas de longa distância para a cabotagem em alguns estados do país. 


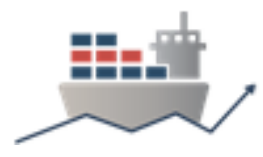

Figura 6 - Porto do Itaqui e a localização dos berços

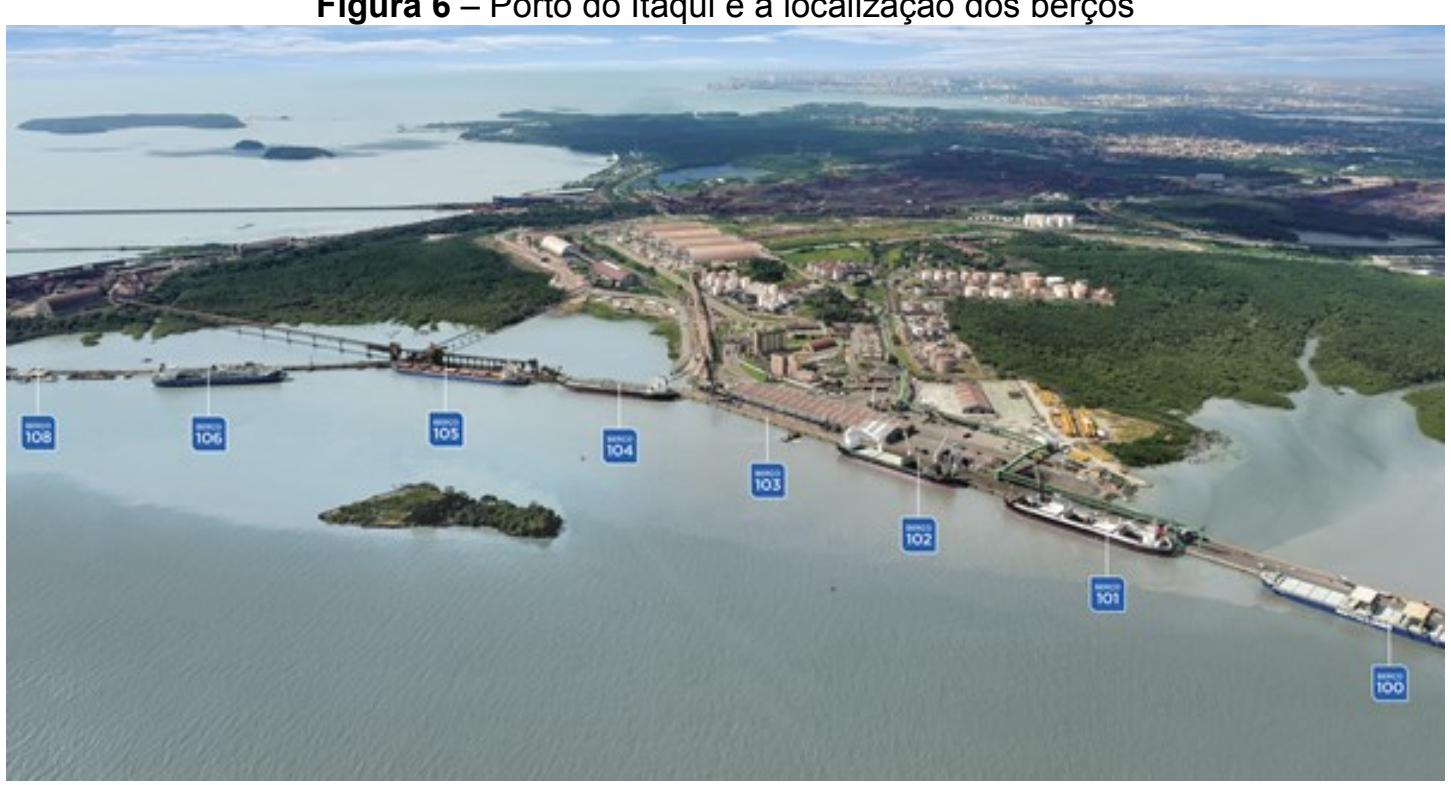

Fonte: Porto do Itaqui, 2019.

O Porto do Itaqui é conhecido por receber navios de grande porte devido suas profundidades que variam de 12 a 19 metros com um total de oito berços operacionais distribuídos condizentes a Figura 6. Possui ligações diretas com a ferrovia Transnordestina (FTL) e a Estrada de Ferro Carajás (EFC). Tem como principais insumos produção de grãos e a movimentação de produtos petrolíferos - importação de diesel e gasolina (PORTO DO ITAQUI, 2019).

Figura 7- Combustível com origem no Maranhão e seus destinos

Origem e Destino (2019)
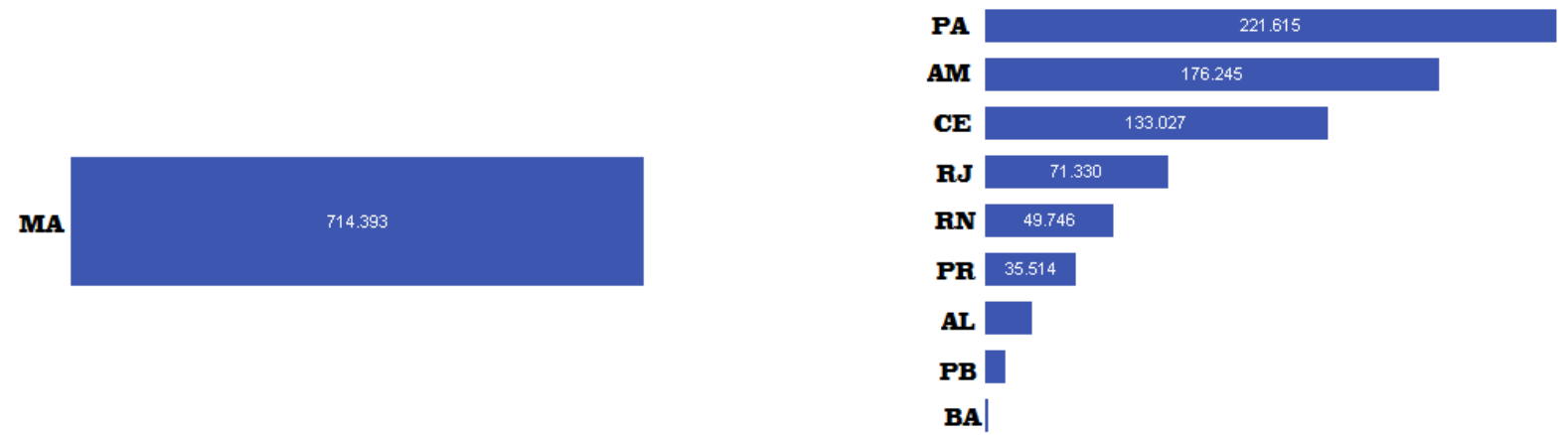

Fonte: Antaq, 2019.

O transporte por Cabotagem já faz parte da realidade do Porto. A figura 7 demonstra os dados quantitativos de navios de combustíveis com origem no Maranhão que segue para diferentes estados do país. Desta forma há de se chamar a atenção para as possibilidades de efetivar a linha regular de cabotagem com o intuito de dinamizar o escoamento de cargas e impulsionar o desenvolvimento da hinterlândia. 
VI CIDESPORT/2019

Congresso Internacional

de Desempenho Portuário
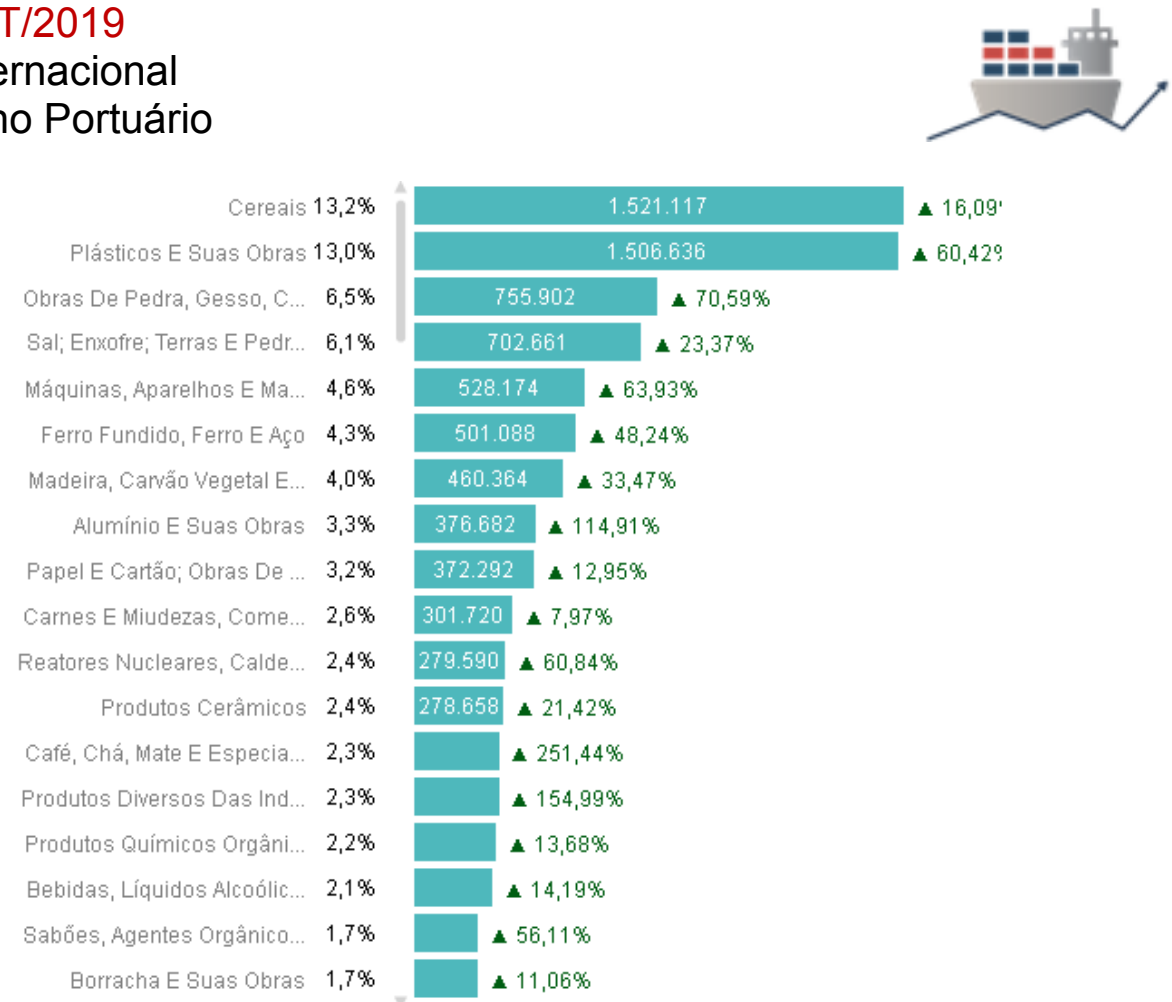

Fonte: ANTAQ, 2019.

O estado possui grandes hipermercados, home centers e industrias que estão carentes de alternativas eficientes para o transporte de suas mercadorias. Conforme pode ser observado na figura 8 grande parte das cargas conteinerizadas de outros portos são referente a produtos desses segmentos.

A partir desses estudos reafirma a importância de buscar alternativas sustentáveis para todos os modais de transporte e utilizar em grande escala os menos onerosos ambientalmente, por isso a matriz equilibrada torna-se uma alternativa eficiente e engloba o tripé da sustentabilidade.

\section{PROCEDIMENTOS METODOLÓGICOS}

Iniciamos o estudo a partir de um resgate acerca do transporte rodoviário e das consequências ambientais que o modal pode ocasionar. Temos como destaque a matriz de transporte brasileira com ênfase na cabotagem. Trazemos dados acerca do comparativo entre os modais para emissão de gás carbônico. Esta pesquisa pauta-se pela análise qualitativa de dados obtidos juntos a órgãos governamentais e não governamentais em âmbito nacional, mas com um foco no Maranhão. Com o objetivo de realizar um estudo contundente acerca da realidade da retomada da linha regular de cabotagem no Porto do Itaqui, optamos pela pesquisa de campo junto a dois gestores da EMAP - Empresa Maranhense de Administração Portuária e uma gestora da empresa especializada em comércio exterior, seguido de um roteiro de entrevista pautado pela estrutura semiaberta. Quanto à análise das entrevistas, deu-se ênfase à análise do conteúdo dos gestores. De acordo com MANZINI (1990/1991, p.150) esta é uma forma de obter informações que outrora só estão disponíveis na memória e no ponto de vista de cada ser.

\section{RESULTADOS}

As entrevistas tiveram dois objetivos principais: análise do panorama atual da cabotagem no complexo portuário de São Luís e análise da vantagem ambiental. 


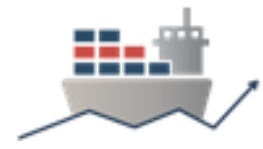

Os entrevistados destacaram pontos vistos por eles como cruciais para o sucesso das operações de cabotagem, como: (a) dificuldades enfrentadas no passado; (b) falta de carga para retornar com o contêiner; (c) falta de industrialização do estado; (d) baixo valor agregado do que é produzido; (e) baixa infraestrutura; (f) falta do interesse dos operadores logísticos em atuar no estado; (g) demanda crescente para o estado; (h) interesse do empresariado local pelo modal; (i) interesse dos empresários após a crise do diesel; (j) benefícios adquiridos para cabotagem; (I) benefícios ambientais.

As entrevistas realizadas aconteceram nos escritórios das empresas, com duração de 1 hora e ocorreram no dia 07 de agosto de 2019, onde se pôde, inclusive, aplicar a técnica da observação. Antes das entrevistas foi informado que não seria gravado. Para não expor os (as) entrevistados (as), todos não foram identificados na transcrição das entrevistas. Por conta disso, a partir deste ponto, todos serão tratados como "Gestor", identificados como "E01", "E02" e "E03". Foi seguido um roteiro de entrevista pautado pela estrutura semiaberta. O Gestor E01 é uma mulher de 33 anos, graduada em Direito. Tem experiência de 15 anos de profissão. O Gestor E02 é uma mulher de 32 anos, graduada em Administração de empresas. Tem amplo conhecimento técnico com uma década de experiência. Dentre os gestores é o que faz mediação entre as empresas interessadas no projeto de retorno da cabotagem e os operadores logísticos. O Gestor E03 é um homem de 52 anos, atua como gerente de operações. Após esta pesquisa de campo, sistematizamos as informações a fim de correlacionar com o referencial teórico, para identificar as perspectivas e os limites da retomada da linha regular de cabotagem no Porto do Itaqui.

\subsection{Visão geral da cabotagem no Complexo Portuário de São Luís}

Segundo o gestor da EMAP especialista em operações, a cabotagem de combustíveis funciona muito bem, a carga é nacionalizada no Itaqui, pois o porto possui um desembaraço menos burocrático e segue para portos de outros estados distribuindo o insumo, quanto às operações com contêineres ainda é algo muito novo para o gestor E03, as informações a respeito da forma que vai ser realizado a operação ainda não esta clara, é sabido por ele que a cabotagem conquistou seus benefícios, pois a EMAP busca contribuir para o projeto, no entanto a sua visão ainda esta atrelada aos problemas que ocorreram no passado.

Para a consultora da empresa especializada em Negócios Internacionais: "a cabotagem precisa funcionar" (E02). A partir do cenário que o país enfrenta e especificamente as necessidades das grandes empresas maranhenses uma solução é necessária para diminuir os custos logísticos. Segundo ela, foram analisados todos os fatores que contribuíram para o fim da linha de cabotagem e buscaram tratativas. Existe um projeto em andamento com sete grandes empresas que se interessaram em realizar o transporte de $30 \%$ de suas mercadorias através da cabotagem. Já foi comprovado que existe demanda, a cabotagem já acontece, no entanto, a carga não chega ao Maranhão através do Porto do Itaqui, mas por meio da ferrovia Transnordestina que recebe a carga do Porto de Pecém. No entanto, devido à ferrovia apresentar uma infraestrutura deficitária o tempo gasto em todo percurso é muito longo, mesmo com esse entrave o frete ainda se torna mais atrativo do que o rodoviário perdendo apenas para o transit time. Foi percebida uma queda de $15 \%$ no custo do frete, tendo uma demanda em julho de 2019 de 500 contêineres mês.

De acordo com a entrevistada, a cabotagem adquiriu alguns benefícios junto a EMAP, como, prioridade de atracação; berço dedicado; desconto nas tarifas portuárias; 
extensão nos prazos de pagamento. Outras mudanças no setor foram com a redução do valor da praticagem para a cabotagem e o Contrato de intenção fechado com o cliente, confirmando uma quantidade mínima. A retirada do ICMS do bunker como foi feito no transporte de longo curso é um ponto ainda em negociação.

Em decorrência da paralisação dos caminhoneiros o Maranhão ainda sofre os reflexos deixados pela crise, a partir desse evento os empresários do estado iniciaram a busca por alternativas eficientes para diminuir a dependência das rodovias e assim o assunto sobre cabotagem recebeu mais atenção e interesse da classe, pois até então se buscava retornar com uma linha regular de cabotagem no porto do Itaqui, mas não havia ímpeto das empresas locais.

O estado é geograficamente favorecido para receber tal transporte, tendo em vista que é passagem obrigatória da escala Pecém - Vila do Conde, onde o projeto busca integrar uma escala no Maranhão.

Vila do Conde já desfruta do sucesso das operações de cabotagem e vive um momento de expansão.

Para atender à capilaridade, a Aliança investiu em embarcações. Ao final de 2017, por exemplo, passou a contar com dois navios de bandeira brasileira da classe 'Exploradores', com capacidade de 3.800 TEUs, que substituíram embarcações mais antigas e menores, dentro da proposta de renovação contínua da frota. Em Outubro deste ano, a empresa substituiu um dos navios de 3800 TEU por uma embarcação da classe "Monte", com capacidade para 5550 TEU.

Com os novos navios, houve incremento de capacidade semanal da ordem de $20 \%$, ampliando a cobertura com um número maior de frequências entre o Sul, Sudeste e Nordeste do País" (TECNOLOGÍSTICA, 2018).

A situação de Pecém não é diferente, segundo o Diário do Nordeste (2019) as operações desse tipo cresceram $56 \%$ no primeiro semestre e com o Projeto BR do Mar que o Governo Federal busca estimular o transporte no país, esses números tende a aumentar. Portos tão próximos estão em uma crescente no setor e o Maranhão caminha em passos curtos para retomar a linha regular de cabotagem.

O maranhão já viveu a experiência de receber navios de cabotagem, no entanto com a falta de carga de retorno, foi um ponto chave para o fim das operações. Com o projeto atual esse problema foi solucionado, os empresários assinaram um contrato se responsabilizando em oferecer uma carga mínima para que o contêiner não volte vazio. Conforme explicou a entrevistada E02 o principal ponto que pode trazer a não efetivação da linha regular de cabotagem no Porto do Itaqui, é a falta de interesse de operadores logísticos. Em 2018 o Itaqui fechou um contrato com a empresa Pedreiras Transportes e um acordo com os principais sindicatos das categorias de trabalhadores do porto o que gerou expectativas de novos empregos no âmbito do OGMO, no entanto uma nova questão foi levanta a empresa não possui um equipamento do tipo MHC para operação com contêiner, ela propôs alugar os equipamentos da Copi Companhia Operadora Portuária do Itaqui, mas isso gerou insegurança, surgindo algumas indagações, tais como: "Quem vai fazer manutenção dos equipamentos, a Pedreiras Transportes ou a Copi" "e se a Copi precisar dos equipamentos como vai ficar as operações?". A Transglobal ofereceu seus serviços, mas os equipamentos que ela possui também não suportam a demanda exigida. O projeto busca iniciar com as empresas que se interessaram, na esperança do sucesso das operações para que futuramente outras firmem parcerias. A Termaco é uma opção, no Maranhão não realiza operações desse porte, mas no Ceará o serviço é oferecido. Ainda não foi 
possível encontrar uma empresa que possua todos os equipamentos adequados para a completa operação de embarque, descarga e desembarque dos navios de contêineres.

Segundo informações extraídas do site da Emap estimasse para inicio das movimentações da cabotagem 1.800 contêineres por mês. Com uma estimativa de 12-15 contêineres movimentação/hora.

Para o navio de cabotagem estimasse também uma janela de atração de 18 horas semanais, com expectativas, e dependo do seu porto de origem, as chegadas entre segundas ou quartas feiras.

Sobre a operação de cabotagem no Porto do Itaqui foi realizada um teste no dia 19 de agosto de 2019 tendo como cliente um hipermercado do estado que trouxe produtos de limpeza, toda movimentação foi acompanhada para que uma analise seja feita e possa dar andamento ao projeto.

Figura 9 - Teste para a retomada da linha regular de cabotagem

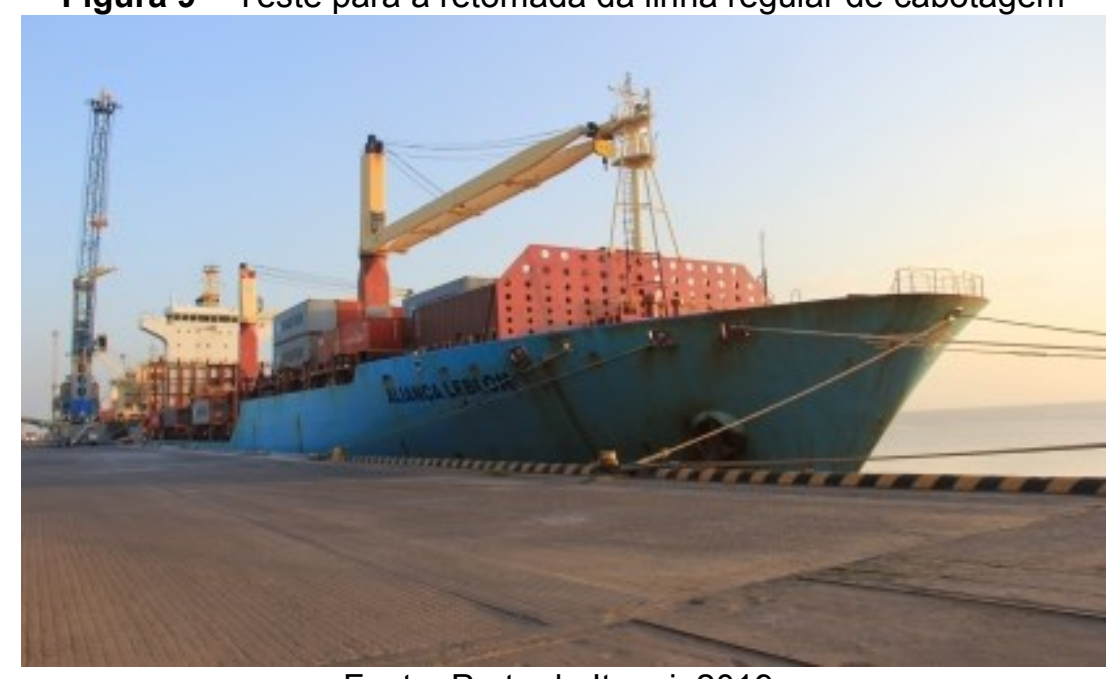

Fonte: Porto do Itaqui, 2019.

Segundo o site do Porto do Itaqui (2019) o navio utilizado foi o Aliança Leblon, de bandeira brasileira, figura 9. Desembarcando 548 toneladas de carga, o teste foi visto com muito entusiasmo pelo presidente da EMAP e as partes interessadas. Com isso, aumentou a esperança da efetivação do transporte no Maranhão e que estas operações possam corroborar para os benefícios ambientais, reduzindo a emissão de $\mathrm{CO} 2$.

\subsection{Vantagens ambientais com a retomada da linha regular de cabotagem no Maranhão}

Ao serem questionados quanto os benefícios trazidos pela cabotagem para redução de CO2 os entrevistados E01 e E03 afirmaram que existe um estudo de controle de particulados no Porto do Itaqui e eles acreditam na importância da cabotagem tanto no aspecto econômico quanto ambiental, percebem que os resultados serão de grande valor para a redução dos gases que causam o efeito estufa.

Para a entrevistada E02 que possui um relacionamento mais próximo com as empresas maranhenses interessadas na retomada da cabotagem foi perguntado se estas reconhecem a relevância do transporte para o meio ambiente e se esse foi um fator para o uso de tal modal, segundo ela algumas empresas tem conhecimento que 


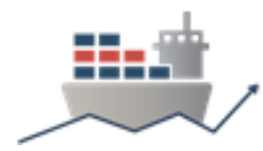

se trata de um transporte mais limpo comparado aos outros, no entanto esse não é o ponto principal, a necessidade pelo transporte em contêineres tem como foco a redução do frete e as consequências ambientais é apenas um fator relevante.

\section{CONSIDERAÇÕES FINAIS}

A cabotagem possui fatores importantes que se enquadram na estrutura e na necessidade do Maranhão para reverter o cenário atual do setor de transporte e tornalo eficaz, mas para isso a ideia de multimodalidade precisa estar mais presente, a integração entre os modais é o ponto chave. Diferente do que muitos pensam a burocracia e o custo do frete deixou de ser o principal gargalo, dando lugar a insegurança por parte dos atores interessados, os operadores logísticos ainda não se sentem atraídos em investir no Maranhão. De acordo com a fala dos entrevistados da EMAP, foi possível notar a descrença também por parte deles no sucesso do projeto, estes ainda possuem uma opinião do que foi vivido no passado da cabotagem.

A troca da rodovia pelo mar vem se tornando uma realidade presente nas grandes empresas, tendo em vista a infraestrutura rodoviária que o Maranhão possui não condizente com a ideia de industrialização. O ponto focal para o desenvolvimento do projeto é conquistar a credibilidade de investidores, o estado é visto como um exportador de comodities não explorando áreas importantes que o tornaria competitivo, aumentando o valor agregado dos seus produtos e atraindo novos parceiros.

O bom desempenho de tal transporte no Porto do Itaqui proporcionará resultados significantes na economia, reduzindo o preço final dos produtos, estimulando empregos diretos e indiretos, impulsionando o crescimento de empresas locais e consequentemente atraindo novas indústrias para o estado.

A respeito dos benefícios ambientais, as empresas participantes do projeto não são diferentes da realidade mundial, o foco para a mudança do transporte tem como principio o lucro, os benefícios ambientais são vistos como consequências e alguns empresários ainda não possui conhecimento da importância do transporte pelo mar para a redução de $\mathrm{CO} 2$, sendo esta uma triste realidade não só do estado, mas como do país que não percebe a necessidade de diversificação do transporte de mercadorias não só para fins econômicos, mas para amenizar um problema que esta em um futuro próximo.

Espera-se que estudo colabore e impulsione futuras pesquisas na área, equilibrando a matriz de transporte brasileira para obter resultados ambientais relevantes. Importante registrar a dificuldade em encontrar na literatura assuntos pertinentes ao tema cabotagem, tal como livros. Outras problemáticas a serem aprofundadas por futuros estudiosos são biocombustíveis para os navios como forma de reduzir a emissão de $\mathrm{CO} 2$ e medidas de proteção para minimizar os impactos na fauna e flora local devido a maior frequência do transporte de cabotagem pela costa.

\section{REFERÊNCIAS}

THE WORLD BANK. Aggregated LPI. Disponível em:

$<$ https://lpi.worldbank.org/international/aggregated-ranking>. Acesso em: 02 Mar. 2019.

CNT. Confederação Nacional do Transporte. Sondagem CNT de Eficiência Energética no Transporte Rodoviário de Cargas. Disponível em: 
VI CIDESPORT/2019

Congresso Internacional

de Desempenho Portuário

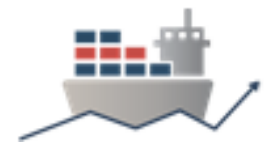

<https://www.cnt.org.br/estudo/sondagem-eficiencia-energetica>. Acesso em: 05 Mar. 2019.

JORNAL DA UNICAMP. Desequilíbrio congestiona matriz de transporte brasileira. Disponível em:

<https://www.unicamp.br/unicamp/index.php/ju/noticias/2018/06/15/desequilibriocongestiona-matriz-de-transporte-brasileira>. Acesso em: 05 Mar. 2019.

BRASIL ESCOLA. A estratégia brasileira de privilegiar as rodovias em detrimento das ferrovias. Disponível em: < https://brasilescola.uol.com.br/geografia/por-que-brasil-adotou-utilizacao-dasrodovias-ao-inves-.htm >. Acesso em: 09 Mar. 2019.

FIESP. "Multimodalidade é essencial para o sistema de transporte brasileiro". Disponível em: < http://www.fiesp.com.br/noticias/multimodalidade-e-essencial-parao-sistema-de-transporte-brasileiro/>. Acesso em: 12 Mar. 2019.

MMA. Ministério do Meio Ambiente. Os Transportes e o Meio Ambiente. Disponível em:<http://www.mma.gov.br/estruturas/secex_consumo/_arquivos/6\%20\%20mcs_transportes.pdf>. Acesso em: 12 Mar. 2019.

CNT. Confederação Nacional do Transporte. O Transporte Move o BrasilProposta da CNT aos Candidatos. Disponível em: < file:///C:/Users/Lays/Downloads/O\%20Transporte\%20Move\%20o\%20Brasil\%20\%20\%C3\%ADntegra.pdf >. Acesso em: 14 Mar. 2019.

O ECO. Gases do Efeito Estufa: Dióxido de Carbono (CO2) e Metano (CH4). Disponível em: < https://www.oeco.org.br/dicionario-ambiental/28261-gases-doefeito-estufa-dioxido-de-carbono-co2-e-metano-ch4/>. Acesso em: 14 Mar. 2019. SEEG BRASIL. Emissões por setor- Energia. Disponível em: <http://plataforma.seeg.eco.br/sectors/energia>. Acesso em: 21 Mar. 2019.

MMA. Ministério do Meio Ambiente. RenovaBio. Disponível em:< http://www.mme.gov.br/documents/1138769/0/P\%26R+-+RenovaBio.pdf/a29044a36315-4845-80d8-832852efbb7f>. Acesso em: 30 Mar. 2019.

ANTAQ. Agência Nacional de Transportes Aquaviários. ANTAQ e Abac debatem navegação de cabotagem. Disponível em:

<http://portal.antaq.gov.br/index.php/2019/03/15/antaq-e-abac-debatem-navegacaode-cabotagem/>. Acesso em: 30 Mar. 2019.

ILLOS. Benefícios que a cabotagem pode trazer para o país. Disponível em: <http://www.ilos.com.br/web/tag/matriz-de-transportes/>. Acesso em: 31 Mar. 2019.

ECOMMERCE BRASIL. Uma comparação da logística dos EUA e Brasil. Disponível em: <https://www.ecommercebrasil.com.br/eblog/2016/01/14/umacomparacao-da-logistica-dos-eua-e-brasil/>. Acesso em: 04 Abr. 2019.

TECNOLOGÍSTICA. O transporte aquaviário brasileiro. Disponível em: <http://www.tecnologistica.com.br/portal/artigos/69038/o-transporte-aquaviariobrasileiro/>. Acesso em: 05 Abr. 2019. 
VI CIDESPORT/2019

Congresso Internacional

de Desempenho Portuário

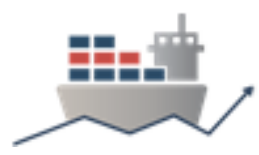

DNIT. Departamento Nacional de Infraestrutura de Transportes. Meio Ambiente e

Hidrovias. Disponível em: <http://www.dnit.gov.br/meio-ambiente/acoes-eatividades/viabilidade-de-hidrovias>. Acesso em: 05 Abr. 2019.

TECNOLOGÍSTICA. Uso de hidrovias e cabotagem: racionalidade na logística brasileira. Disponível em:

<http://www.tecnologistica.com.br/portal/artigos/69317/hidrovias-cabotagemracionalidade-logistica-brasileira/>. Acesso em: 05 Abr. 2019.

PORTOGENTE. Transporte Rodoviário. Disponível em: <https://portogente.com.br/portopedia/73414-transporte-rodoviario>. Acesso em: 25 Abr. 2019.

G1 NATUREZA. Diesel responde por $\mathbf{5 3} \%$ da emissão de gás carbônico no trânsito no Brasil. Disponível em: $<$ http://g1.globo.com/natureza/noticia/2011/02/diesel-responde-por-53-da-emissaode-gas-carbonico-no-transito-no-brasil.html>. Acesso em: 25 Abr. 2019.

G1 NATUREZA. Diesel responde por $\mathbf{5 3} \%$ da emissão de gás carbônico no trânsito no Brasil. Disponível em:

$<$ http://g1.globo.com/natureza/noticia/2011/02/diesel-responde-por-53-da-emissaode-gas-carbonico-no-transito-no-brasil.html>. Acesso em: 25 Abr. 2019.

CNT. Confederação Nacional do Transporte. Transporte Rodoviário. Disponível em:<file:///C:/Users/Lays/Documents/ARTIGO/estudo_transporte_rodoviario_infraest rutura.pdf>. Acesso em: 25 Abr. 2019.

ANTAQ. Agência Nacional de Transportes Aquaviários. A importância do porto brasileiro no desenvolvimento da cabotagem- Container. Disponível em: <http://portal.antaq.gov.br/wp-content/uploads/2016/12/\%E2\%80\%9CA Import\%C3\%A2ncia-do-Porto-Brasileiro-no-Desenvolvimento-da-Cabotagem\%E2\%80\%93-Container\%E2\%80\%9D-Luiz-Antonio-Cristov\%C3\%A3o-Balau.pdf>. Acesso em: Acesso em: 25 Abr. 2019.

ANTAQ. Agência Nacional de Transportes Aquaviários. A importância do porto brasileiro no desenvolvimento da cabotagem. Disponível em: <http://portal.antaq.gov.br/wp-content/uploads/2016/12/\%E2\%80\%9CAImport\%C3\%A2ncia-do-Porto-Brasileiro-no-Desenvolvimento-daCabotagem\%E2\%80\%9D-Fabrizio-Pierdomenico.pdf>. Acesso em: Acesso em: 25 Abr. 2019.

ANTAQ. Agência Nacional de Transportes Aquaviários. Aumenta o transporte no longo curso e na cabotagem. Disponível em:

<http://portal.antaq.gov.br/index.php/2019/02/18/aumenta-o-transporte-no-longocurso-e-na-cabotagem/>. Acesso em: Acesso em: 25 Abr. 2019.

BARTHOLOMEU, Daniela Bacchi; PERA, Thiago Guilherme; CAIXETA-FILHO, José Vicente. Logística sustentável: avaliação de estratégias de redução das emissões de CO2 no transporte rodoviário de cargas. J. Transp. Lit., Manaus, v. 10, n. 3, p. 1519, Sept. 2016 . Disponível em: 
VI CIDESPORT/2019

Congresso Internacional

de Desempenho Portuário

<http://www.scielo.br/scielo.php?script=sci_arttext\&pid=S2238-

$10312016000300015 \&$ Ing=en\&nrm=iso >. Acesso em: 09 ago. 2019.

access on 09 Ago. 2019.

BARTHOLOMEU, Daniela Bacchi; CAIXETA FILHO, José Vicente. Impactos econômicos e ambientais decorrentes do estado de conservação das rodovias brasileiras: um estudo de caso. Rev. Econ. Sociol. Rural, Brasília, v. 46, n. 3, p. 703-738, Sept. 2008 . Disponível em:

$<$ http://www.scielo.br/scielo.php?script=sci_arttext\&pid=S0103-

20032008000300006\&lng=en\&nrm=iso>. Acesso em: 09 ago. 2019.

CATELA, Eva Yamila da Silva; SEABRA, Fernando. Aglomerações produtivas e escolha de modal de transporte: um estudo de caso do setor industrial de São Paulo e Manaus.Nova econ., Belo Horizonte, , v. 27, n. 2, p. 295-321, Aug. 2017

. Disponível em: <http://www.scielo.br/scielo.php?script=sci_arttext\&pid=S010363512017000200295\&lng=en\&nrm=iso>. Acesso em: 09 ago. 2019.

FACHINELLO, Arlei Luiz; NASCIMENTO, Sidnei Pereira. Cabotagem como alternativa para o transporte de carnes da região Sul para o Norte/Nordeste brasileiro: um estudo de caso. Rev. Econ. Sociol. Rural, Brasília, v. 46, n. 4, p. 969-988, Dec. 2008 . Disponível em:

$<$ http://www.scielo.br/scielo.php?script=sci_arttext\&pid=S0103-

$20032008000400003 \&$ Ing=en\&nrm=iso>. 09 ago. 2019.

GONÇALVES, L.M.; FILHO, A. C. D.; ALVES, M. T. A.; NASCIMENTO, S. M. R.; MACIEL, C. S. Cabotagem uma alternativa econômica de transporte eficaz para o brasil. 01 Jun. 2011. Disponível em:

https://doaj.org/article/f9171e80bbb541c38a4ae39330c86094 . 11 ago. 2019.

BORGES, I. B.; GONÇALVES, W.; RESEARCH, R. R. F. Análise da ampliação das rotas de cabotagem sob ponto de vista econômico e sustentabilidade do negócio. 01 June 2018. Disponível em:

https://rsd.unifei.edu.br/index.php/rsd/article/view/434/335. . 11 ago. 2019.

MOURA, D. A.; BOTTER, R. C. O transporte por cabotagem no Brasil. Potencialidade para a intermodalidade visando a melhoria do fluxo logístico. Pro- dução (online), v. 11, n. 2, 2011. Disponivel em:

https://www.producaoonline.org.br/rpo/article/download/897/798. 11 ago. 2019.

SOUSA,R.A.; Leopoldino, C. B. Avaliação da cabotagem como opção de modal logístico: estudo de caso de uma metalúrgica nordestina. GEPROS. Gestão da Produção, Operações e Sistemas, Bauru, Ano 14, n³, jul-set/2018, p. 295-

324. Disponível em:

https://revista.feb.unesp.br/index.php/gepros/article/view/1963/861. 11 ago. 2019.

SILVEIRA, A. J., PIRES, J. S., BARBOSA, E. R., PEREIRA, C. H.; SOUSA, M. A. (2012). Cabotagem como instrumento de preservação ambiental. Cabotagem como instrumento de preservação ambiental. In: XXVII Congresso da ANPET, 2013, Belém. Anais do XVII Congresso da ANPET. Disponível em:

https://www.researchgate.net/publication/258514172_Cabotagem_como_Instrument o_de_Preservacao_Ambiental-2. 11 ago. 2019 
VI CIDESPORT/2019

Congresso Internacional

de Desempenho Portuário

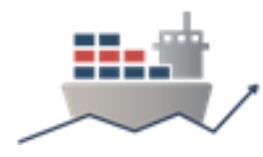

TEIXEIRA, Cássio Adriano Nunes et al. Navegação de cabotagem brasileira.

BNDES Setorial, Rio de Janeiro, n. 47 , p. [391]-435, mar. 2018. Disponível em: http://web.bndes.gov.br/bib/jspui/handle/1408/15385. 11 ago. 2019.

TECNOLOGÍSTICA. Vila do Conde ganha serviço de cabotagem dedicado da Aliança. Disponível em:

$<$ https://www.tecnologistica.com.br/portal/noticias/78807/vila-do-conde-ganhaservico-de-cabotagem-dedicado-da-alianca/>. Acesso em: 13 ago. 2019.

Diário do Nordeste. Com incentivo, Pecém pode ser principal ponto de cabotagem do NE. Disponível em:

$<$ https://diariodonordeste.verdesmares.com.br/editorias/negocios/com-incentivopecem-pode-ser-principal-ponto-de-cabotagem-do-ne-

1.2132660?utm_source=whatsapp\&utm_medium=button-share $>$. Acesso em: 13 ago. 2019.

EMAP. Porto do Itaqui pronto para retomada da linha regular de contêineres. Disponível em: http://www.portodoitaqui.ma.gov.br/imprensa/noticia/porto-do-itaquipronto-para-retomada-da-linha-regular-de-conteineres. Acesso em 13 ago. 2019

BrasilAlemanha News. O entrave da cultura "rodoviarista" na logística brasileira. Disponível em: <http://www.brasilalemanhanews.com.br/coluna-em-destaque/oentrave-da-cultura-rodoviarista-na-logistica-brasileira/>. Acesso em: 20 ago. 2019.

MMA. Ministério do Meio Ambiente. Efeito Estufa e Aquecimento Global. Disponível em:<https://www.mma.gov.br/informma/item/195-efeito-estufa-eaquecimento-global>. Acesso em: 20 Ago. 2019.

ANTAQ. Agência Nacional de Transportes Aquaviários. Anuário Transporte Via Cabotagem. Disponível em: <http://web.antaq.gov.br/ANUARIO/>. Acesso em: 20 Ago. 2019.

ANTAQ. Agência Nacional de Transportes Aquaviários. Anuário Transporte Via Cabotagem. Disponível em: <http://web.antaq.gov.br/ANUARIO/>. Acesso em: 20 Ago. 2019.

MANZINI, E.J. Considerações sobre a elaboração de roteiro para entrevista semi-estruturada. In: MARQUEZINE: M. C.; ALMEIDA, M. A.; OMOTE; S. (Orgs.) Colóquios sobre pesquisa em Educação Especial. Londrina:eduel, 2003. p.11-25. Acesso em: 27 ago. 2019

EMAP. Infraestrutura. Disponível em: <http://www.portodoitaqui.ma.gov.br/porto-doitaqui/infraestrutura>. Acesso em 31 ago. 2019 